\title{
Neurology
}

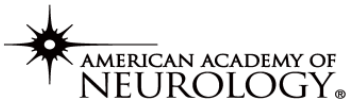

The most widely read and highly cited peer-reviewed neurology journal

The Official Journal of the American Academy of Neurology

Neurology Publish Ahead of Print

DOI: 10.1212/WNL.0000000000013151

Teaching NeuroImage: Arteriovenous Fistula of Cauda Equina Fed by the Proximal

\section{Radicular Artery}

Author(s):

Conghui $\mathrm{Xu}, \mathrm{MD}^{1}$; Jun Lin, $\mathrm{MD}^{2}$; Xiaodong Niu, $\mathrm{MD}^{3}$; Jin Li, MD, $\mathrm{PhD}^{3}$

Equal Author Contributions:

Conghui $\mathrm{Xu}$ and Jun Lin are co-first authors.

Neurology® Published Ahead of Print articles have been peer reviewed and accepted

for publication. This manuscript will be published in its final form after copyediting,

page composition, and review of proofs. Errors that could affect the content may be

corrected during these processes. 


\section{Corresponding Author:}

Jin $\mathrm{Li}$

lijinhuaxi@126.com

Affiliation Information for All Authors: 1.Department of Radiology, Chengdu Shangjin Nanfu Hospital, Sichuan University, Chengdu, PR China; 2.Department of Operating Room, Chengdu Shangjin Nanfu Hospital, Sichuan University, Chengdu, China; 3.Department of Neurosurgery, West China Hospital of Sichuan University, Chengdu, China.

\section{Contributions:}

Conghui $\mathrm{Xu}$ : Drafting/revision of the manuscript for content, including medical writing for content; Major role in the acquisition of data

Jun Lin: Drafting/revision of the manuscript for content, including medical writing for content; Major role in the acquisition of data

Xiaodong Niu: Drafting/revision of the manuscript for content, including medical writing for content; Study concept or design

Jin Li: Drafting/revision of the manuscript for content, including medical writing for content; Study concept or design

Number of characters in title: 74

Abstract Word count: 0

Word count of main text: 100

References: 2

Figures: 2

Tables: 0

Neuroimage Legend Count: 50

Supplemental: Teaching Slides\&\#65292;Checklists.

Search Terms: [ 3 ] Arteriovenous malformation, [ 252 ] All Spinal Cord

\section{Acknowledgements: None.}

Study Funding: The authors report no targeted funding

Disclosures: The authors report no disclosures relevant to the manuscript. 


\section{Abbreviations}

AVF: Arteriovenous fistula

ASA: Anterior spinal artery

MRI: Magnetic resonance imaging

PRA: Proximal radicular artery

\section{MAIN TEXT}

A 66-year-old man presented with a 2-year history of weakness and numbness in his lower limbs and occasional urinary incontinence. Spinal MRI showed spinal edema and prominent flow voids. Selective angiography of right T10 segmental artery revealed an arteriovenous fistula of cauda equina (CEAVF) fed by the proximal radicular artery (PRA), the downward extension of anterior spinal artery (Figure 1). Intraoperatively, the fistula, draining vein, and feeding artery running along a nerve root were identified. The fistula was resected successfully (Figure 2) and the symptoms gradually improved. Spinal CEAVF is extremely rare. ${ }^{1,2}$ This case demonstrates the microscopic angioarchitecture of CEAVF. 
Appendix 1. Authors

\begin{tabular}{|c|c|c|}
\hline Name & Location & Contribution \\
\hline Conghui & Shangjin & Drafting/revision of the manuscript for content, \\
\hline \multirow[t]{2}{*}{$\mathrm{Xu}, \mathrm{MD}$} & Hospital, Sichuan University, & including medical writing for content; Major role \\
\hline & Chengdu, China & in the acquisition of data \\
\hline Jun Lin, & Shangjin Nanfu & Drafting/revision of the manuscript for content, \\
\hline \multirow[t]{2}{*}{ MD } & Hospital, Sichuan University, & including medical writing for content; Major role \\
\hline & Chengdu, China & in the acquisition of data \\
\hline Xiaodong & West China Hospital of Sichuan & Drafting/revision of the manuscript for content, \\
\hline Niu, MD & University, Chengdu, China & $\begin{array}{l}\text { including medical writing for content; Study } \\
\text { concept or design }\end{array}$ \\
\hline Jin Li, MD, & West China Hospital of Sichuan & Drafting/revision of the manuscript for content, \\
\hline $\mathrm{PhD}$ & University, Chengdu, China & including medical writing for content; Study \\
\hline
\end{tabular}

[AZ 11.12.2021] 176029 Teaching Slides -- $\underline{\text { http://links.lww.com/WNL/B687 }}$

\section{References}

1. Ohtonari T, Ota S, Nishihara N, et al. Arteriovenous Fistula in a Nerve Root of the Cauda Equina Fed by a Proximal Radiculo-Medullary Artery. Interventional Neuroradiology [online serial]. 2011;17:217-223. Accessed at: http://journals.sagepub.com/doi/10.1177/159101991101700213 (Epub 2011 Jun 20).

2. Tanioka S, Toma N, Sakaida H, Umeda Y, Suzuki H. A case of arteriovenous fistula of the cauda equina fed by the proximal radicular artery: anatomical features and treatment precautions. European Spine Journal [online serial]. 2018;27:281-286. Accessed at: http://link.springer.com/10.1007/s00586-017-5129-0 (Epub 2017 May 13). 
Figure Legends:

Figure 1. Preoperative Spinal MRI and DSA

(A, B) Preoperative MRI shows spinal edema and prominent flow voids (arrows). (C, D) Angiography shows a CEAVF (arrowhead) fed by the PRA.
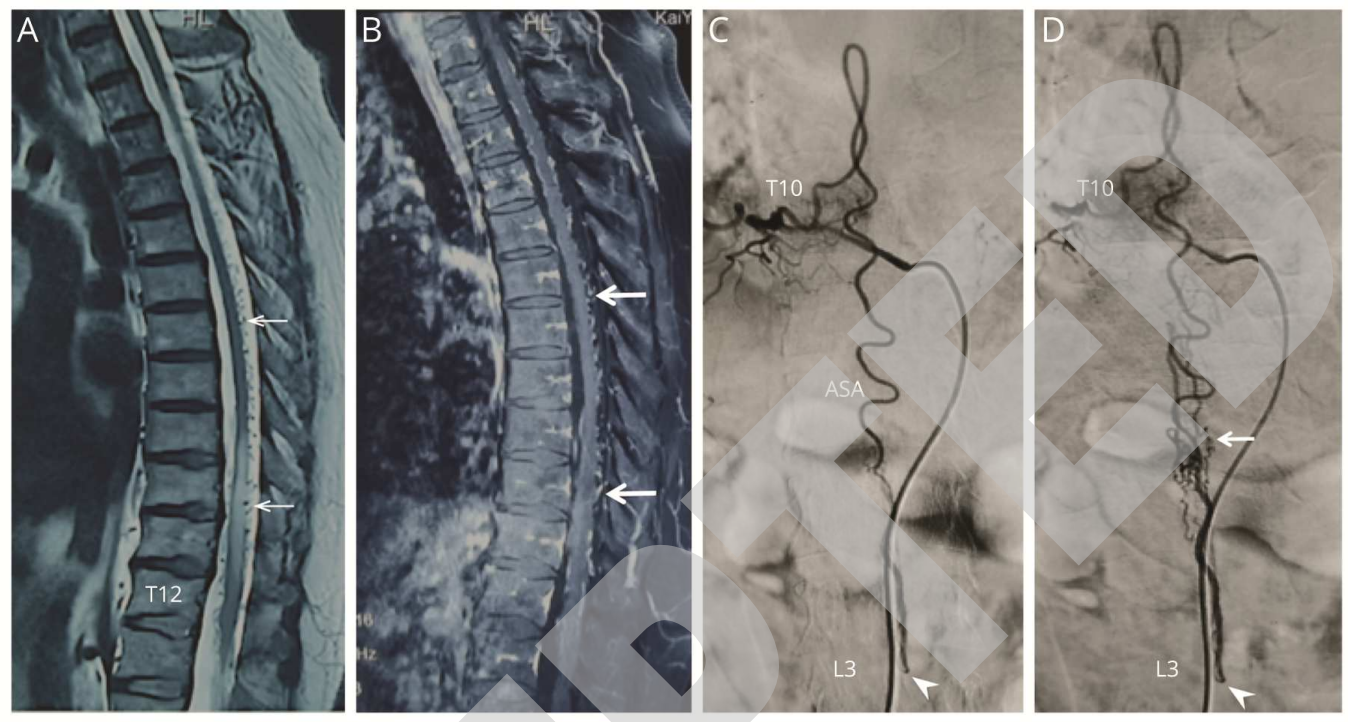

Figure 2. Intraoperative and Postoperative Images

(A, B) Intraoperative images show the microscopic angioarchitecture of CEAVF. The filum terminale (FT) is not involved. (C, D) Postoperative MRI reveals reduced edema and flow voids.
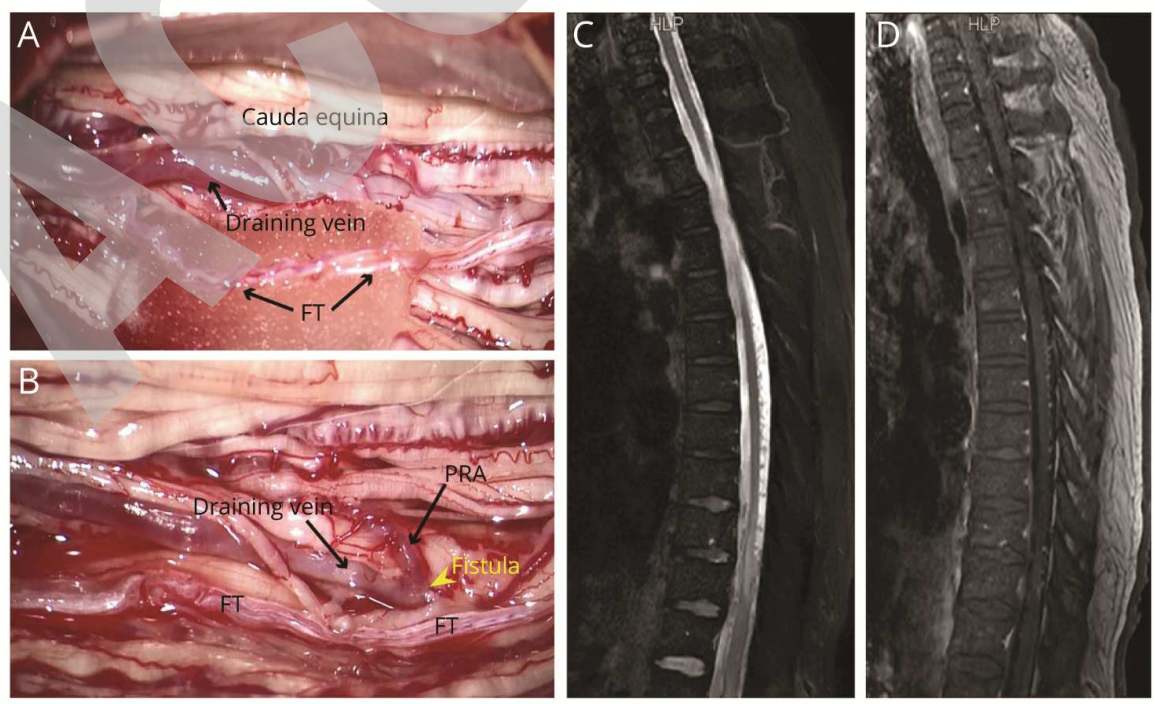


\title{
Neurology
}

\author{
Teaching NeuroImage: Arteriovenous Fistula of Cauda Equina Fed by the Proximal \\ Radicular Artery \\ Conghui Xu, Jun Lin, Xiaodong Niu, et al. \\ Neurology published online December 6, 2021 \\ DOI 10.1212/WNL.0000000000013151
}

\section{This information is current as of December 6, 2021}

Updated Information \&

Services

Subspecialty Collections

Permissions \& Licensing

Reprints including high resolution figures, can be found at:

http://n.neurology.org/content/early/2021/12/06/WNL.0000000000013151. citation.full

This article, along with others on similar topics, appears in the following collection(s):

All Spinal Cord

http://n.neurology.org/cgi/collection/all_spinal_cord

Arteriovenous malformation

http://n.neurology.org/cgi/collection/arteriovenous_malformation

Information about reproducing this article in parts (figures, tables) or in its entirety can be found online at:

http://www.neurology.org/about/about_the_journal\#permissions

Information about ordering reprints can be found online:

http://n.neurology.org/subscribers/advertise

Neurology $\AA^{\circledR}$ is the official journal of the American Academy of Neurology. Published continuously since 1951, it is now a weekly with 48 issues per year. Copyright (C) 2021 American Academy of Neurology. All rights reserved. Print ISSN: 0028-3878. Online ISSN: 1526-632X.

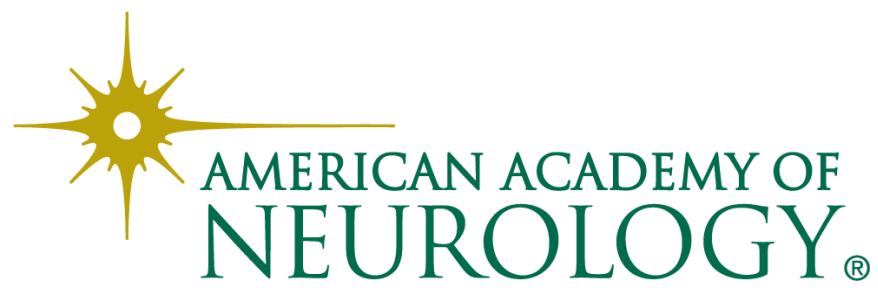

